\title{
Corporate Social Responsibility: Dimensions and Challenges in Bangladesh
}

\section{Mohammad Awal Hossen}

Senior Lecturer, Department of Business Administration, Leading University, Sylhet-3100, BANGLADESH

*Corresponding Contact:

Email: ahossen178@gmail.com

Mobile: +88-01670727194

\begin{abstract}
This paper aims at exploring the dimensions and challenges of corporate social responsibility (CSR) in the context of Bangladesh, taking Carroll's CSR Pyramid as a conceptual framework for explicative analysis. Carroll's CSR Pyramid is by far the most well-known framework of CSR, which gives relative importance to economic, legal, ethical and discretionary (philanthropic) obligations of corporations towards society. As the countries differ in their economical, social and political conditions around the globe, the dimensions of CSR and the challenges in executing CSR initiatives also differ. This study found that the dimensions currently in practice and applicable to Bangladesh do not follow the same order as proposed by Carroll in the context of developed countries. It is suggested that the relative priorities of CSR in case of Bangladesh are to be in the following order: economic, philanthropic, environmental, legal and ethical responsibilities. Finally, some suggestions for successful execution of CSR initiatives are also given.
\end{abstract}

Key Words: Corporate social responsibility (CSR), CSR dimensions, CSR challenges, developing countries, Bangladesh

\section{INTRODUCTION}

Although the concept of Corporate Social Responsibility (CSR) exists in academic literature for a long time (Carroll, 1999), agreement on how CSR concept should be defined and executed has created a significant debate among researchers, companies and communities. Still, there is no universally accepted definition of CSR (Garriga and Mele, 2004). CSR is treated as the assumed obligations of corporate houses to society. Socially responsible businesses are businesses that maximize the positive impacts and minimize the negative impacts on society where the businesses operate (consumers, employees, suppliers, communities, local government, and employers). CSR also denotes to business activities linked to compliance with legal framework, ethical norms and values, respect for communities, people and the natural environment. CSR is now being gradually seen as an essential attribute and a set of obligations of a modern corporate house. According to Knox, Maklan and French (2005:8), "Corporate social responsibility is something that every board must now address in some form." CSR is developed on the perception that corporate houses 
are in a close interrelationship with other interests in, for example - economical, legal, ethical, environmental and community systems because business operations do affect and are being affected by - such interests in the community (Dobers and Halme, 2009).

In Bangladesh, CSR practices in the form of philanthropic activities have a long history which includes donations to poor people, different charitable organizations and religious institutions (Miyan, 2006). Although CSR seems to be a new issue in the corporate environment of Bangladesh, it is gaining momentum in the present days. Over the past few decades, business executives, government officials and policy makers in Bangladesh put economic obligations before social duties for accelerating the flow of economic development (Quazi, 1994). The society also supported this emphasis and neglected the adverse impacts of business activities (such as environmental pollution) for ensuring national growth. According to National Geographic, Bangladesh ranked as the first nation most vulnerable to the impacts of the climate change in the coming decades. The Germanwatch Global Climate Risk Index 2010 has revealed that climate change in the form of natural calamities has caused a great loss of lives and economic growth in Bangladesh over the last few decades (Harmeling, 2010). Furthermore, the country lacks the financial, human, institutional and technical resources and capabilities required to face the adverse impacts of climate change and natural disasters (Islam, 2009). This gives a special message to all the concerned parties to take initiatives to be prepared for long term adaptation. State efforts can be supplemented by the companies in this regard. The legal responsibilities of business get a lower priority compared to other dimensions of CSR in Bangladesh. There is a far less pressure for companies from the government to perform their operations within the established legal framework. Furthermore, according to all major ranking institutions, Bangladesh can routinely be found among the most corrupted countries in the world. Ethics in Bangladesh seems to have least importance on the CSR agenda.

A.B. Carroll seems to be the most cited author in the area of CSR. According to Carroll (1979; 1991), "The social responsibility of business encompasses the economic, legal, ethical and discretionary expectations that society has of organizations at a given point in time" (p. 500). Carroll shows CSR as comprising of four dimensions; namely, economic, legal, ethical and discretionary. In 1991, Carroll (1991) showed these four dimensions in the structure of a Pyramid; known as CSR Pyramid. Economic responsibility of business is placed in the first layer of the pyramid, followed by legal, ethical and discretionary responsibility. This emphasis is based on studies in an American context. Different empirical studies found that culture has an impact on the importance given by business and stakeholders to CSR (Burton et al., 2000; Edmondson et al., 1999; Pinkston et al., 1994). This study attempts to accomplish three objectives: 1) to use Carroll's CSR Pyramid to see whether there is any difference in the layers of CSR Pyramid in the context of Bangladesh; 2) to understand the challenges that companies are facing in executing CSR, and 3) to provide some suggestions for successful execution of CSR.

\section{LITERATURE REVIEW}

Historically, CSR has been seen as a developed country issue. Therefore, a good number of research articles can be found in the context of developed countries on CSR literature, practice and theory. On the other hand, academic research on CSR literature, practice and theory in case of developing countries remains poor (Belal, 2000). 1950s is recognized as the beginning of the era of modern CSR. In this decade, corporations started to feel that they exist as the society exists and they have some responsibilities to the society. Several studies of this decade discussed about the responsibilities of the corporations for achieving the purposes, values and policies for the society (Bowen, 1953; Heald, 1957). Howard R. Bowen (1953) is one of the early 
prominent writers of CSR. According to Bowen, "CSR refers to the obligations of businessmen to pursue those policies, to make those decisions or to follow those lines of actions which are desirable in terms of the objectives and values of our society (p.6)."

World Business Council for Sustainable development has given a comprehensive definition of CSR. In its publication, Making Good Business Sense by Lord Holme and Richard Watts; defined CSR as, "the continuing commitment by business to behave ethically and contribute to economic development while improving the quality of life of the workforce and their families as well as of the local community and society at large" (World Business Council for Sustainable Development, 2008).

A.B. Carroll seems to be the most cited author in the area of CSR. According to Carroll, "The total corporate social responsibility of business entails the simultaneous fulfillment of the firm's economic, legal, ethical and philanthropic responsibilities. Stated in more pragmatic and managerial terms, the CSR firm should strive to make a profit, obey the law, be ethical, and be a good corporate citizen (Carroll, 1991, p. 43)." Carroll presented that corporations have four types of responsibilities to the society. Economic development of the country is the most important obligation of the corporations. Corporations must obey the law of the country, operate within the legal framework and pay taxes to the government duly. Next, businesses have to perform their activities within the expectations of the society and to do what is right, just and fair. Finally, businesses must be good corporate citizens and supplement state efforts where necessary. In 1991, Carroll presented these dimensions in the form of a Pyramid model; known as CSR Pyramid model. It is shown below:

Figure 1: The Pyramid of Corporate Social Responsibility (Carroll, 1991)

\begin{tabular}{|c|c|c|}
\hline $\begin{array}{l}\text { Be a good corporate } \\
\text { citizen }\end{array}$ & $\begin{array}{l}\text { Philanthropic } \\
\text { Responsibilities }\end{array}$ & $\begin{array}{l}\text { Contribute resources to the community; } \\
\text { improve quality of life }\end{array}$ \\
\hline Be ethical & $\begin{array}{c}\text { Ethical } \\
\text { Responsibilities }\end{array}$ & $\begin{array}{l}\text { Obligation to do what is right, just and } \\
\text { fair. Avoid harm }\end{array}$ \\
\hline Obey the law & $\begin{array}{c}\text { Legal } \\
\text { Responsibilities }\end{array}$ & $\begin{array}{l}\text { Law is society's codification of right } \& \\
\text { wrong. Play by the rules of the game. }\end{array}$ \\
\hline Be profitable & $\begin{array}{c}\text { Economic } \\
\text { Responsibilities }\end{array}$ & $\begin{array}{l}\text { The foundation on which all } \\
\text { other rests. }\end{array}$ \\
\hline
\end{tabular}

In Bangladesh, CSR practices in the form of philanthropic activities have a long history which includes donations to poor people, different charitable organizations and religious institutions (Miyan, 2006). Although CSR seems to be a new issue in the corporate environment of Bangladesh, it is gaining momentum in the present days for two important reasons. Firstly, the pressure from all the stakeholders to practice CSR and corporate houses that do not practice CSR will face a threat from the stakeholders (Belal, 2001). Secondly, practicing CSR increases the reputation of the companies and promotes better stakeholder return (Kabir, 2003). In Bangladesh, concentrating on CSR practice will be helpful, not only for promoting corporate governance, ensuring labor rights and safety of the workplace, improving community development and environmental management; but also for industrial growth and for accessing the global market. At present, several dimensions of CSR are in practice in Bangladesh (Miyan, 2006 and Mondol, 2009).

Most of the studies conducted on CSR in Bangladesh mainly focused on the disclosure of the companies' CSR activities in their Annual Reports (Belal, 1999, 2000a, 2000b, 2001, 2006; 
Belal \& Owen, 2007; Imam, 2000). Belal (2001) in his research, studied the sample annual reports of 30 companies enlisted in DSE and Dhaka Metropolitan Chamber of Commerce and found that the information provided by these companies on CSR practices was very poor and this information was mainly qualitative in nature. Furthermore, studies conducted by Imam (2000) and Hossain et al. (2005) revealed a similar picture. However, in a later study, Sobhani et al. (2009) found that the status of overall disclosure of CSR practices has increased over the past few years. Duarte \& Rahman (2010) also showed that the awareness of Bangladeshi managers regarding CSR practices, concepts and barriers has increased.

Uddin et al. (2008) argues that companies in Bangladesh should take three dimensions into consideration; namely economic, social and environmental and ecological aspects to be successful and finally discussed about some CSR measuring techniques. Graafland and Van de Ven (2006) found that two major dimensions impel companies to practice CSR; these are moral motives and strategic motives. Farah and Newman (2010) showed that consumers do not support companies engaged in irresponsible social activities, whereas, Olsen (2006) revealed that consumers support companies engaged in responsible social behaviors by purchasing their products. Hence, corporations are gradually involving in socially responsible actions as they become aware that consumers value socially responsible businesses (Levy, 1999) and CSR also helps to improve the financial performance of the firm ( Handelman and Arnold, 1999).

It is well recognized that there is far less research on corporate social responsibility in developing countries than in developed countries. The need of CSR is more articulated in developing countries since there are gaps in social needs and governance of CSR. In such circumstances, businesses tend to come forward to understand the necessities and expectations to fill those gaps (Baughn et al., 2007). Observing the studies conducted on CSR from the perspective of developing countries or changing economies, it can be found that little is done (Luken, 2006). This further indicates that research conducted on CSR in the contexts of developed countries may not be well applicable in the contexts of developing countries (Prieto-Carrón et al., 2006; Fox, 2004). This paper is an endeavor to give concentration to CSR issues in developing countries, in this case in the context of Bangladesh.

\section{ReseARCh Methodology}

This research paper is a descriptive study in nature. Being descriptive in nature, this paper has been prepared after reviewing and studying a large number of articles on CSR published in different journals, periodicals, working paper, conference paper, web site, and different writers' published books on CSR. The collected information has been extensively analyzed and the experience and academic knowledge of the author have been utilized for preparing this paper.

\section{DIMENSIONS OF CSR IN BANGLADESH}

Most of the studies based on Carroll's (1991) CSR Pyramid, consisting of economic, legal, ethical and discretionary responsibilities have been done in the context of developed countries. Different empirical studies found that culture has an impact on the importance given by business and stakeholders to CSR (Burton et al., 2000; Edmondson et al., 1999; Pinkston et al., 1994). It can also be seen in the context of Bangladesh as one of the developing countries. This paper attempts to reflect whether there is any difference in the layers of CSR Pyramid provided by Carroll (1991) in the context of Bangladesh.

An important dimension of CSR is environmentally conscious management which has been overlooked in Carroll's CSR Pyramid. In the recent past, businesses didn't count environment as an important element and many of the advancements in industrial sectors 
have come often at the cost of the environment (Daily \& Huang, 2001). Businesses should pay attention to all their stakeholders while doing business. Natural environment, as one of the stakeholders is affected by the activities of business. Environmentally conscious management can lead to various social and economic progresses in different regions, which is one of the main objectives of CSR (Cruz \& Pedroze, 2009:1176). According to German Watch's Global Climate Risk Index (CRI) of 2011, Bangladesh is the most vulnerable nation to climate change in the world which demands special attention to environmental protection compared to other developed and developing countries. Businesses, as one of the subsystems of the society should specially work for the protection of the environment. However, in Bangladesh economic obligations of business to society get the highest priority followed by philanthropic obligations. Taking Carroll's CSR Pyramid and all these issues in consideration, the following CSR Pyramid is suggested for Bangladesh:

Figure 2: Corporate Social Responsibility Pyramid applicable to Bangladesh

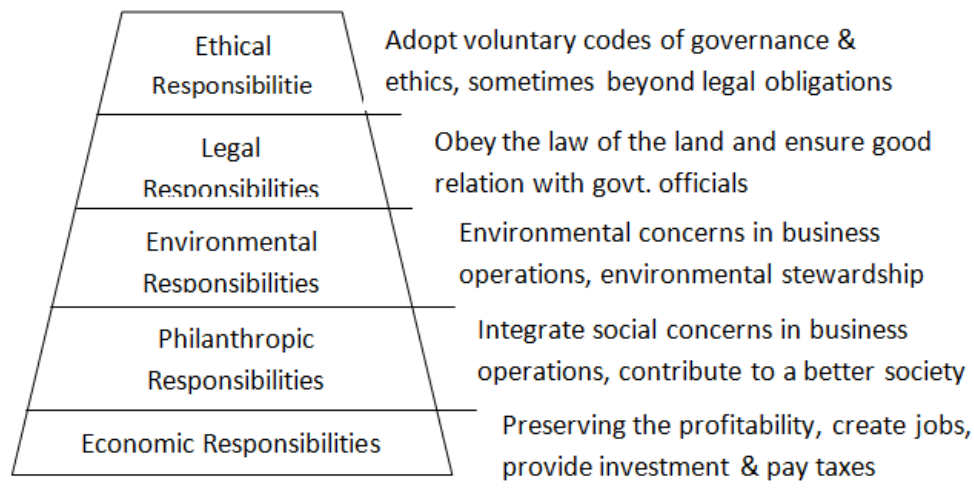

Source: author

\section{Economic Responsibilities}

Bangladesh is one of the poorest countries in the world. The country is suffering from a shortage of foreign direct investment, high unemployment and abysmal poverty. Furthermore, the government is not so affluent to solely contribute to the economic development of the country. That's why; economic contribution of the business is highly appreciated by the government and the society. Economic contribution of business is often regarded as the most important and influential factor to make a social impact. Since independence, companies in Bangladesh have contributed in economic growth in the form of tax payment, infrastructure development, employment generation and poverty reduction. Over the past few years, Bangladesh has taken private sector development as the strategy to enhance economic growth. Since 1990s, the country has achieved significant economic growth and has been positioned as the $10^{\text {th }}$ most rapidly expanding economy among 31 large developing countries. Bangladesh averaged a GDP growth rate of $6 \%$ between the years of 2004 to 2014. Fox (2004) also advocated that the economic contribution done by companies in developing countries should be seen as a developmentoriented approach to CSR which helps to gain sustainable development.

\section{Philanthropic Responsibilities}

In Bangladesh, philanthropic responsibilities of business get a higher priority than other dimensions of CSR due to the socio-economic needs of the people. Philanthropy is seen as an expected norm here. CSR practices in Bangladesh have a long history of philanthropic activities which include donations to poor people, different charitable organizations and religious 
institutions (Miyan, 2006). Most of the first generation businesses in Bangladesh are family owned and they are involved in community development through charity. The CSR World Wide Portal (2012) concluded that, the civil society, businesspeople and politicians in Bangladesh view CSR in terms of philanthropy. This is also consistent with the view that, over the last few years, most of the developmental projects in Bangladesh have become reliant on foreign aid and donor assistance. Companies also think that it is easier to involve in CSR through philanthropic activities.

\section{Environmental Responsibilities}

According to National Geographic, Bangladesh ranked as the first nation most vulnerable to the impacts of the climate change in the coming decades. The geographical location and geomorphological conditions of Bangladesh have made the country one of the most vulnerable ones to climate change, particularly to sea level rise. The country has a very low and flat topography, except the northeast and southeast regions. About $10 \%$ of the country is hardly $1 \mathrm{~m}$ above the mean sea level (MSL), and one-third is under tidal excursions (Ali, 1999); which gives a warning to all the concerned parties to take measures to be prepared for long term adaptation. The companies of the country can supplement state efforts in this regard. Taking all these issues in mind, this study stresses that environmental responsibilities of businesses should be counted as one of the dimensions of CSR, specially in the context of Bangladesh. It means companies should run business in a way that ensures waste minimization, pollution prevention and the elimination of health and safety hazards. To protect the environment companies should administer health and safety assessments; formulate policies regarding environmental management and practice environmental management methods. Furthermore, environmentally conscious management can lead to various social and economic progresses in different regions, which is one of the main objectives of CSR (Cruz \& Pedroze, 2009:1176).

\section{Legal Responsibilities}

In Bangladesh, the legal responsibilities of business get a lower priority compared to other dimensions of CSR. There is a far less pressure for companies from the government to perform their operations within the established legal framework. In Bangladesh, CSR tends to be less institutionalized in terms of CSR codes, policies and guidelines compared to most of the developed countries. This is because; the authorities responsible for law enforcement lack the administrative efficiency, autonomy and resources required for the successful implementation of the established rules and regulations. Bangladesh also lagging behind the developed world in case of implementing human rights and labor rights practices into the legislation. Furthermore, tax avoidance by companies is seen as a socially irresponsible behavior, which is a common scene in Bangladesh.

\section{Ethical responsibilities}

Ethical responsibilities of business in Bangladesh get the least priority compared to other dimensions of CSR. According to all major ranking institutions, Bangladesh can routinely be found among the most corrupted countries in the world. According to TI's Global Corruption Perception Index 2015, Bangladesh is the $13^{\text {th }}$ most corrupted country in the world and $2^{\text {nd }}$ most corrupted country in South Asia. The World Bank's Investment Climate Survey routinely showed Bangladesh as one of the most poorly ranked countries and revealed that corruption is still affecting the business to a large extent. Due to the poor performance of the law enforcing authority, companies can bend the law when it is helpful for them. The absence of good corporate governance has promoted many unethical business practices and a poor CSR culture among the companies in Bangladesh, especially in the private sector (Miyan, 2006). Hence, ethics in Bangladesh seems to have lest importance on the CSR agenda. 


\section{ChALLENGES OF CSR In BANGLADESH}

Lack of community awareness regarding CSR: There is a lack of awareness among the general public about CSR activities in Bangladesh, which is required to make CSR initiatives more fruitful. Various stakeholders including the media can take an active role in generating the awareness of common public in this area. This will help to change the attitude of the public towards the different CSR activities taken by the companies and encourage other companies to actively join in CSR initiatives needed to improve the health, education and quality of life of the people in this region.

Lack of coordination among the stakeholders: There is a lack of coordination of activities among the stakeholders including the local community, local government, private companies, media, employees and society at large which is creating barriers in administering CSR initiatives. There is a gap of pragmatic and functional models of involvement among all three important stakeholders-the government, the NGOs and the private corporate houses. Therefore, an effective strategy should be taken to bridge the gaps between different parties while taking a sustainable perspective on CSR.

Engagement of a few companies: It has been found that only a limited number of large and medium sized companies are engaged in CSR activities and they are operating in some specific areas of the country. It calls up an urgent need to involve other small and medium enterprises (SMEs) in the CSR domain to reach a wider geographic region. Ultimately, this will result in an increase in the quality of health, education and ensure sustainable development.

Absence of well-trained non-governmental organizations: It is found that there is a lack of well trained and organized non-governmental organizations (NGOs) that can effectively identify the actual needs of the specific community and work jointly with the companies to successfully implement CSR initiatives. NGOs can help to develop project based CSR initiatives keeping in mind the actual needs of the community and work collaboratively with the companies for effective implementation.

Lack of expertise of private sector entrepreneurs: Many of the private sector entrepreneurs are not aware of the concept of CSR. They lack the expertise needed to successfully implement CSR activities matched with the actual necessity of the community. Even CSR can be used as a business model and can be done in a cost effective way aligning with the objectives of the business. Hence, it calls for some steps taken by the concerned parties for educating the private sector entrepreneurs.

Lack of proper enforcement of laws and regulations: In our country, the authorities responsible for designing and enforcing laws and regulations are not capable enough and lack the resources necessary to implement the laws and regulations. However, improperly executed labor laws, weak unions and absence of consumer rights groups and corruption of the regulatory authorities are making CSR violation uncontrollable.

Non-availability of proper CSR codes and guidelines: The government of the country still does not have any CSR policy and guidelines for the companies. Without a specific CSR policy it will be impossible to monitor and control CSR violation. Only Bangladesh Bank plays a significant role in promoting CSR activities within the banking industry. Hence, issue specific CSR codes, standards and guidelines should be formulated for proper execution of CSR initiatives.

The Absence of state intervention: There is an absence of state intervention in the public interest that allows private entrepreneurs to behave in a socially irresponsible way and violate existing laws. Therefore, there is a need to increase capacity building on the part of the state to intervene effectively in case of violation of laws by private sector entrepreneurs.

Non-recognition of effective CSR initiatives: The government still does not give any recognition in the form of rewards to the companies engaged in successful implementation of CSR covering the poor and underprivileged sections of the society. Recognition by the government will motivate other companies to actively participate in improving the condition of the community. Hence, incentives need to be offered to the CSR practicing corporate houses. 
Lack of media coverage: There is a lack of media coverage of different CSR initiatives taken by the companies. The media is not concerned about highlighting the good stories and generating the awareness of the common people about various CSR initiatives taken by the companies. Such coverage can act as a promotional activity for the companies and also motivate other companies to contribute in community development.

Lack of research in the area of CSR: CSR is relatively a new concept in Bangladesh which is gaining momentum in the recent years. It is found that there is a lack of research in the area of CSR. Though the universities are providing some courses on CSR, but the issue is still in its infancy age. The government should provide funds for conducting research in this area.

Lack of CSR-based disclosures by companies: Several studies showed that companies in Bangladesh do not fully disclose information on the nature of social practices and much of the information provided is descriptive in nature. Studies also found that it is due to the lack of statutory requirements to disclose information on social practices.

\section{Suggestions For Successful EXECUTION OF CSR PRACTICES}

- A specific CSR policy, highlighting the expectations that the government has of the companies should be designed. Mandatory provisions pertaining to CSR practices should be formulated. The government can also provide guidelines to the companies for implementing CSR initiatives.

- Community participation and contribution to CSR activities of companies should be increased through various awareness building programs.

- Special training programs for private sector entrepreneurs and NGOs regarding CSR should be conducted.

- The government should give rewards in the form of recognition to the companies effectively engaged in community development.

- The government as well as different companies should consider seeking assistance from outside bodies for the successful outcome of CSR initiatives.

- The government should provide fund for conducting research in this area. Specific CSR activities should be identified by analyzing the actual needs of different communities.

- Companies should voluntarily incorporate CSR into their vision and formulate a specific CSR strategy. They should not wait for government policy.

- The law enforcing authorities and regulatory bodies should be more concerned regarding non compliance of issues pertaining to CSR. The government should equip these authorities with more power and resources, and violation of existing laws should be strictly controlled.

- Different authorities of the government, companies and the civil society can jointly organize seminars and open discussions on different issues pertaining to CSR and its effective implementation.

- Media should play an active role in building awareness of the common people regarding CSR. They should highlight the CSR initiatives taken by different companies.

- In developing the CSR strategy businesses should identify those with an interest in the initiatives undertaken and originate a guideline for maintaining relationship with them.

- While formulating CSR strategies, companies should identify the indicators of performance and they should routinely evaluate performance against the indicators to ensure that CSR strategies are being implemented.

- Companies can open a separate CSR department or office with a senior person responsible for administering CSR compliance and implementation.

- Businesses should voluntarily disclose their CSR engagement to the general public. Such disclosure will enhance their credibility and create opportunities for other businesses to coordinate their activities.

- Higher education institutions involved in business administration should design courses regarding various CSR activities and they should have collaboration with different companies. 


\section{CONCLUSION}

Corporate Social Responsibility (CSR) is no more a western world issue. The need of CSR is more articulated in developing countries since there are gaps in social needs and governance of CSR. Although CSR seems to be a new issue in the corporate environment of Bangladesh, it is receiving importance in the present days.CSR practices in Bangladesh are mainly dominated by the discretionary (or philanthropic) conception and do not give emphasis on sustainable development. However, CSR initiatives taking sustainable outcomes and environmental aspects into consideration are important and need to be developed. Companies must pursue their obligations towards society to improve conditions in a sustainable fashion. In Bangladesh, concentrating on CSR practice will be helpful, not only for promoting corporate governance, ensuring labor rights and safety of the workplace, improving community development and environmental management; but also for industrial growth and for accessing the global market.

\section{REFERENCES}

Alam, N., \& Rubel, A. (2014). Impacts of Corporate Social Responsibility on Customer Satisfaction in Telecom Industry of Bangladesh. ABC Journal Of Advanced Research, 3(2), 26 - 37.

Ali, A. (1999). "Climate Change Impacts \& Adaptation Assessment in Bangladesh", Climate Research, Vol. 12, pp. 109-116.

Baughn, C.C., Bodie, N.L.D. and McIntosh, J. C. (2007), “Corporate Social and Environmental Responsibility in Asian Countries and Other Geographical Regions", Corporate Social Responsibility and Environmental Management, Vol. 14 No. 4, pp.189-205.

Belal, A. R. (2000a), "Corporate Social Performance Reporting in Bangladesh. Managerial Auditing Journal", Vol.15 No.3, pp. 133-141.

Belal, A. R. and Owen, D. L. (2007), "The views of corporate managers on the current state of, and future prospects for, social reporting in Bangladesh", Accounting, Auditing \& Accountability Journal, Vol. 20 No. 3, pp. 472-494.

Belal, A.R. (1999), "Corporate Social Reporting in Bangladesh", Social and Environmental Accounting, Vol.19 No.1, pp. 8-12.

Belal, A.R. (2000b), "Environmental Reporting in Developing Countries: Empirical Evidence from Bangladesh", Eco Management and Auditing, Vol. 7 No. 3, pp. 114-121.

Belal, A.R. (2001), "A study of corporate social disclosures in Bangladesh", Managerial Auditing Journal, Vol.16 No. 5, pp. 274.

Bowen, H.R. (1953), Social responsibilities of the businessman, Harper \& Row, New York, NY

Burton, B.K., Farh, J.L. and Hegarty, W. H. (2000), "A Cross-Cultural Comparison of Corporate Social Responsibility Orientation: Hong Kong vs. United States Students", Teaching Business Ethics, Vol. 4 No. 2, pp.151-167.

Cruz, L.B., and Pedrozo, E.A. (2009), "Corporate Social Responsibility and Green Management: Relation between Headquarters and Subsidiary in Multinational Corporations", Management Decision, Vol. 47 No. 7, pp. 1174-1199.

Daily, B.F., and Huang, S. (2001), “Achieving Sustainability through Attention to Human Resource Factors in Environmental Management", International Journal of Operating \& Production Management, Vol. 21 No.12, pp. 1539-1552.

Deitiana, T. (2015). The Determinant of CSR Disclosure of Mining Industry Listed in Indonesia Stock Exchange. Asian Business Review, 5(3), 141-148. doi:http://dx.doi.org/10.18034/abr.v5i3.664

Dobers, P. and Halme, M. (2009), "Corporate social responsibility and developing countries", Corporate Social Responsibility and Environmental Management, Vol. 16 No. 5, pp. 237-249.

Duarte, F. P. and Rahman, S. (2010), "Perceptions of Corporate Social Responsibility by Bangladeshi Managers: An Exploratory Study", International Review of Business Research Papers, Vol. 6 No. 5, pp. 119-136. 
Edmondson, V.C. and Carroll, A.B. (1999), “Giving Back: An Examination of the Philanthropic Motivations, Orientations and Activities of Large Black-Owned Businesses", Journal of Business Ethics, Vol. 19 No. 2, pp. 171-179.

Farah, M.F. and Newman, A.J. (2010), “Exploring consumer boycott intelligence using a socio-cognitive approach", Journal of Business Research, Vol. 63 No.4, pp. 347-55.

Ferdous, M., \& Moniruzzaman, M. (2015). An Empirical Evidence of Corporate Social Responsibility by Banking Sector based on Bangladesh. Asian Business Review, 3(4), 82-87. doi:http://dx.doi.org/10.18034/abr.v3i4.283

Graafland, J. and Van de Ven, B. (2006), "Strategic and moral motivation for corporate social responsibility", Journal of Corporate Citizenship, Vol. 22, pp. 111-123.

Handelman, J.M., and Arnold, S.J.(1999), " The role of marketing actions with a social dimension: appeals to the institutional environment", Journal of Marketing, Vol. 63. pp. 33-48.

Heald, M. (1957), "Management's responsibility to society: The growth of an idea", The Business History Review, Vol. 31 No. 4, pp. 375-384.

Imam, S. (2000), "Corporate social performance reporting in Bangladesh", Managerial Auditing Journal, Vol. 15 No. 3, pp. 133.

Islam, M., \& Hasan, M. (2016). Corporate Social Responsibility of Commercial Bank in Bangladesh: A Comparative Study on Nationalized and Private Banks. Asian Business Review, 6(1), 25-34. doi:http://dx.doi.org/10.18034/abr.v6i1.780

Islam, N. (2009), 'Stop climate change, save Bangladesh'. The Daily Star, 26 September.

Karen, L., Becker-Olsen, B., Andrew, C. and Ronald P.H. (2006), “The impact of perceived corporate social responsibility on consumer behavior", Journal of Business Research, Vol. 59, pp. $46-53$.

Knox, S., Maklan, S. and French, P. (2005), "Corporate social responsibility: Exploring stakeholder relationships and programme reporting across leading FTSE companies", Journal of Business Ethics, Vol. 61 No. 1, pp. 7-28.

Luken, R.A. (2006), “Where Is Developing Country Industry in Sustainable Development Planning?", Sustainable Development, Vol. 14 No. 1, pp. 46-61.

Miyan M.A. (2006), "Dynamics of Corporate Social Responsibility - Bangladesh Context”, Journal of AIUB Bangladesh, Vol. 3 No. 1, pp. 13-32.

Mohammad, N., \& Kamal, S. (2016). Social Impact and Sustainability of Corporate Social Responsibility in the Banking Sectors: Bangladesh Perspective. Asian Business Review, 6(1), 39-46. doi:http://dx.doi.org/10.18034/abr.v6i1.802

Pinkston, T.S. and Carroll, A.B. (1994)' "Corporate Citizenship Perspectives and Foreign Direct Investment in the US", Journal of Business Ethics, Vol. 13 No. 3, pp. 157-169.

Quazi, A. (1994), "Social responsibility, consumerism and corporate behaviour: A comparative study of managerial attitudes and marketing action in Australia and Bangladesh", Unpublished PhD thesis, School of Marketing, University of New South Wales, Australia.

Siddique, M. (2014). CSR Practices and Competitive Advantages: A Descriptive Study. American Journal Of Trade And Policy, 1(3), 109 - 116.

Sobhani, F.A., Amran, A. and Zainuddin. (2009), "Revisiting the practices of corporate social and environmental disclosure in Bangladesh", Corporate Social - Responsibility and Environmental Management, Vol. 16, pp. 167-183. 